Oostveen, C.J. van, Goedhart, N.S., Francke, A.L., Vermeulen, H. Combining clinical practice and academic work in nursing: a qualitative study about perceived importance, facilitators and barriers regarding clinical academic careers for nurses in university hospitals. Journal of

Clinical Nursing: 2017, 26(23-24), 4973-4984

\begin{tabular}{l|l} 
Postprint & 1.0
\end{tabular}

Version

Journal website http://onlinelibrary. wiley.com/doi/10.1111/jocn.13996/abstract;jsessionid=1F446D DB0C2F608F737F5A3F0BE37E65.f04t03

Pubmed link https://www.ncbi.nlm.nih.gov/pubmed/?term=28793367

DOI $\quad 10.1111 /$ jocn.13996

This is a NIVEL certified Post Print, more info at http://www.nivel.eu

\title{
Combining clinical practice and academic work in nursing: A qualitative study about perceived importance, facilitators and barriers regarding clinical academic careers for nurses in university hospitals
}

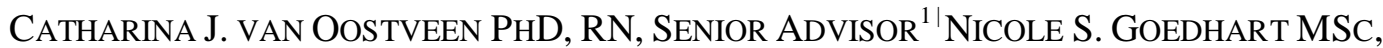
JUNIOR LECTURER AND RESEARCHER ${ }^{2 \mid}$ ANNEKE L. FRANCKE PHD, NURSING PROFESSOR VU AND PROGRAMME COORDINATOR NURSING CARE - NIVEL ${ }^{3,4}$ HeSTER VERMEULEN PHD, NURSING PROFESSOR ${ }^{5}$

1Spaarne Gasthuis Academy, Spaarne Gasthuis Hospital, Hoofddorp, The Netherlands 2Athena Institute for Research onInnovation and Communication in Health and Life Sciences, Faculty of Science, VU University, Amsterdam, The Netherlands

3Amsterdam Public Health Research Institute, VU University Medical Center, Amsterdam, The Netherlands

4Netherlands Institute for Health ServicesResearch (NIVEL), Utrecht, The Netherlands 5Department of IQ Healthcare Radboud Institute of Health Sciences, Scientific Center for Quality of Healthcare, Nijmegen, The Netherlands

\footnotetext{
ABSTRACT

Aims and objectives: To obtain in-depth insight into the perceptions of nurse academics and other stakeholders regarding the importance, facilitators and barriers for nurses combining clinical and academic work in university hospitals.

Background: Combining clinical practice and academic work facilitates the use of research findings for high-quality patient care. However, nurse academics move away from the bedside because clinical academic careers for nurses have not yet been established in the Netherlands.

Methods: This qualitative study was conducted in two Dutch university hospitals and their affiliated medical faculties and universities of applied sciences. Data were collected between May 2015 and August 2016. We used purposive sampling for 24 interviews. We asked 14 participants in two focus groups for their perceptions of importance, facilitators and barriers in nurses' combined clinical and academic work in education and research. We
} 
Oostveen, C.J. van, Goedhart, N.S., Francke, A.L., Vermeulen, H. Combining clinical practice and academic work in nursing: a qualitative study about perceived importance, facilitators and barriers regarding clinical academic careers for nurses in university hospitals. Journal of Clinical Nursing: 2017, 26(23-24), 4973-4984

audiotaped, transcribed and thematically analysed the interviews and focus groups.

Results: Three themes related to perceived importance, facilitators and barriers: culture, leadership and infrastructure. These themes represent deficiencies in facilitating clinical academic careers for nurses. The current nursing culture emphasises direct patient care, which is perceived as an academic misfit. Leadership is lacking at all levels, resulting in the underuse of nurse academics and the absence of supporting structures for nurses who combine clinical and academic work.

Conclusions: The present nursing culture appears to be the root cause of the dearth of academic positions and established clinical academic posts.

Relevance to clinical practice: A culture change would require a show of leadership that would promote and enable combined research, teaching and clinical practice and that would introduce clinical academic career pathways for nurses. Meanwhile, nurse academics should collaborate with established medical academics for whom combined roles are mainstream, and they should take advantage of their established infrastructure for success.

\section{1| BACKGROUND}

Combining clinical and academic work in nursing benefits the quality, safety and efficiency of patient care because it facilitates the use of research (Aiken et al., 2011; AUKUH 2013; Buchan, 1999; Latter, Richardson, \& Fader, 2010; Segrott, McIvor, \& Green, 2006).

The articulation of clinically relevant questions inspires researchers in their research, which has an impact on the quality of nurses' daily activities. Nurses who are involved in generating scientific knowledge are also more willing to implement this knowledge afterwards (Staffileno, Wideman, \& Carlson, 2013). Furthermore, nurses who combine clinical practice and education further the distribution of best clinical practices among other nurses, nursing students and lecturers (Weir \& Ozga, 2010). This is very important because nurses' use of research findings is often limited (Eskes, Storm-Versloot, Vermeulen, \& Ubbink, 2012; Ozsoy \& Ardahan, 2008; Wangensteen, Johansson, Bj€orkstr€om, \& Nordstr€om, 2011).

Increasingly, more weight is being put on nurses' work because of the focus on prevention and self-management in patient care in Europe (EU 2014). Apparently, the lack of strong, visible clinical and academic leadership, role models, and organisational support is detrimental, and now, we have a low level of evidencebased practice in nursing (Logan, Gallimore, \& Jordan, 2016; Oude Rengerink et al., 2013; Ubbink, Guyatt, \& Vermeulen, 2013). Therefore, particularly university hospitals should aid and encourage nurses who are willing to combine clinical practice and academic work: they are the clinical nurse academics (Coombs, Latter, \& Richardson, 2012; Latter et al., 2010; Staffileno et al., 2013). These nurses are potential role models and should be given robust pathways to become strong, visible leaders in clinical practice (Coombs et al., 2012).

Clinical academic careers have a long history in medicine; combining clinical and academic work is a common good for physicians internationally. 
Oostveen, C.J. van, Goedhart, N.S., Francke, A.L., Vermeulen, H. Combining clinical practice and academic work in nursing: a qualitative study about perceived importance, facilitators and barriers regarding clinical academic careers for nurses in university hospitals. Journal of Clinical Nursing: 2017, 26(23-24), 4973-4984

This has resulted in a large body of evidence about various medical conditions, advanced knowledge transfer of research results to medical practice and high-quality patient care. Moreover, medical leaders who are hierarchically highly positioned are often the ones who have combined clinical and academic work during their careers. Some hospitals even mandatorily require those seeking high positions to combine clinical and academic work. The governance philosophy of such hospitals is "professionals in the lead". However, the employment conventions are not always conducive to nurturing nurse academics - the available clear pathways are limited for nurses who want to pursue a career that combines clinical and academic work. The history of nursing as a service discipline shows how this has come about (van Oostveen, Mathijssen, \& Vermeulen, 2015). However, as nurses lack opportunities to combine clinical and academic work, they do not meet the same standards as other professionals do for high positions, and they are by definition not equally empowered.

Substantial numbers of nurses are still working in an environment of limited expectations of their involvement in research. Since the early 2000 s, there has been a growing body of literature about initiatives to increase research capacity and capability, especially with regard to clinical academic career pathways (Weir \& Ozga, 2010).

Implementation of a clinical academic career pathway for nurses would increase the recruitment and retention of clinical nurse academics (AUKUH 2013; Coombs et al., 2012; Latter et al., 2010).

Such a pathway visualises career possibilities for nurses in clinical practice, research and education. It would contribute to the development of clinically skilled and academically robust professionals. These pathways would also create flexible career opportunities for nurses and attract nurses to clinically focused research early in their careers (Latter, Clark, Geddes, \& Kitsell, 2009).

Even though the need and added value seem evident, clinical academic career pathways in university hospitals are conspicuously absent in the Netherlands. This results in a low number of postacademically trained nurses combining clinical and academic work

because they leak away to staff advisor positions in hospitals, to credentialing bodies, or to purely educational posts at universities of applied sciences. Apparently, these nurses find employment in positions far from the operational level, while their impact on direct patient care with regard to quality, safety and efficiency is marginal. Not enough information exists about the perceived importance, facilitators and barriers for nurses' combined clinical practice and academic work in the Netherlands. Insight into these perceptions would ignite the discussion about the need for nurses to combine clinical and academic work (why) and facilitate the design and implementation of clinical academic pathways in the Netherlands (how). Therefore, the aim of this study was to obtain insight into the perceptions of nurses, researchers, educators, policymakers, human resource managers and both nursing and medical directors about nurses' combined clinical and academic work in university hospitals in the Netherlands.

\section{$2 \mid$ METHODS}

The design and execution of our study complied with the COnsolidated criteria for REporting Qualitative studies (COREQ) checklist (Tong, Sainsbury, \& Craig, 2007). 
Oostveen, C.J. van, Goedhart, N.S., Francke, A.L., Vermeulen, H. Combining clinical practice and academic work in nursing: a qualitative study about perceived importance, facilitators and barriers regarding clinical academic careers for nurses in university hospitals. Journal of Clinical Nursing: 2017, 26(23-24), 4973-4984

\section{1 | Design}

A qualitative study design using semi-structured interviews with researchers, educators, policymakers and directors, as well as focus groups of nurses, was used to obtain insight into the perceived importance, facilitators and barriers for nurses' combined clinical and academic work.

\subsection{Setting and organisational structure}

The study was conducted in two Dutch university hospitals and their partnered medical faculties and universities of applied sciences. The board of directors of hospital 1 consisted of two medical staff members and one financial staff member, while the board of hospital 2 consisted of two financial staff members and one medical staff member.

In both hospitals, each specialty division was managed by a three-person board: a medical director, a nursing director and a financial director. Each division consisted of a number of nursing wards, managed on the tactical level by physicians and on operational level by head nurses. The medical and financial directors were responsible for budgets. All medical directors were postacademically trained, had obtained a master of business administration degree at INSEAD and were appointed as clinical professors. All physicians were postacademically $(\mathrm{PhD})$ trained, and all financial staff members had master-level qualifications. Nursing directors and head nurses were qualified nurses with additional management training. A few held master degrees, but this was not a requirement. The nursing skill mix consisted of registered nurses with a master degree focused on clinical and research skills, registered nurses with a bachelor degree in nursing and registered nurses with vocational nursing education. In Dutch hospitals, at the time of this study, no distinction was made in function, role or tasks between bachelor and vocationally trained nurses. Neither hospital had positions for Chief Nursing Officers (CNOs) or Chief Nursing Informatics Officers (CNIOs).

In hospital 1, most postacademically trained nurses were positioned in policy departments or appointed as quality and safety advisors to the nursing directors. In hospital 2, they were appointed in a research institute without clinical basis. The partnered medical faculties and universities of applied sciences were both located near the university hospitals. Strategic policy reported that $70 \%$ of the trained lecturers had master's degrees and 58\% had PhDs in the partnered universities of applied sciences of both hospitals. This level is set for all faculties, including nursing. The percentages of master or $\mathrm{PhD}$ trained nursing lecturers are comparable to those of other faculties, taking into account the ratio of lecturers to the number of students (De Jonge, 2016).

\section{[TABLE 1] [TABLE 2]}

\section{3 $\mid$ Participants}

A purposive sample was used for the 24 semi-structured interviews and the two focus groups. Maximum variation sampling (Polit \& Beck, 2012) was used to gain information-rich data from those who had interests in clinical academic careers for nurses either as nurses, educators, nursing directors, nursing managers, physicians or medical directors (Table 1). 
Oostveen, C.J. van, Goedhart, N.S., Francke, A.L., Vermeulen, H. Combining clinical practice and academic work in nursing: a qualitative study about perceived importance, facilitators and barriers regarding clinical academic careers for nurses in university hospitals. Journal of Clinical Nursing: 2017, 26(23-24), 4973-4984

We intentionally invited $47(23+24)$ nurses to participate in the focus groups. The response rates were $25 \%$ for hospital 1 and $35 \%$ for hospital 2 (Table 2). The main reason for declining the invitation was work commitments to direct patient care.

\section{4 | Data collection}

One researcher conducted the individual semi-structured interviews between May 2015 and September 2015. We used a semi-structured guideline for both the interviews and the focus groups. The guideline was based on Helfrich, Weiner, Mckinney, and Minasian's (2007) theoretical framework for implementation effectiveness of complex interventions. In this framework, culture, innovation fit and value, the presence of an innovation champion, management support and financial resource availability are crucial concepts (Box 1). A draft of a Dutch clinical academic career pathway was shown to introduce the concept to the participants during the interviews and the focus groups (Figure 1). The researchers designed this concept on the basis of the AUKUH Clinical Academic Careers Group for Nursing and Midwifery (2013) "Clinical Academic Career Pathways" design. This clinical pathway was chosen because it includes all aspects of the trias academica - the three services of universities: education, research and clinical work.

We sent each participant an email with information about the aim of the study and an invitation to participate. After the participants gave their approval, they received a copy of indicative main questions, as recommended by Erlandson, Harris, Skipper, and Allen (1993), to allow them to prepare their responses so that we could obtain rich information.

\section{[BOX 1]}

\section{5 | Interviews}

The interviews were conducted at a time and location that participants preferred, in the native language of each, and each interview took between 30 and $60 \mathrm{~min}$. Each participant was interviewed once.

Probes and prompts were used as questioning techniques (Polit \& Beck, 2012). The interviews were audio-recorded with the participants' permission, and notes were made immediately after each interview. All participants received a summarised version of their interview for confirmation. Changes made to the summaries were used for data analysis.

\section{6 | Focus groups}

The focus groups lasted approximately $1 \mathrm{hr}$ and were audiorecorded with the full agreement of all participants. The focus groups had a single-category design, based on the creative diamond model of Tassoul and Buijs (2007). This model was used because it allowed participants to be creative and helped cluster the themes.

The focus groups consisted of three rounds, starting with a divergent phase in which themes were identified. Next, the themes were clustered on the basis of relation. Lastly, a convergence towards the most important themes took place (Tassoul \& Buijs, 2007). 
Oostveen, C.J. van, Goedhart, N.S., Francke, A.L., Vermeulen, H. Combining clinical practice and academic work in nursing: a qualitative study about perceived importance, facilitators and barriers regarding clinical academic careers for nurses in university hospitals. Journal of Clinical Nursing: 2017, 26(23-24), 4973-4984

\section{[FIGURE 1]}

\section{7 | Researchers' roles}

Two researchers were involved in the process of data collection (NG and HV). HV is a clinical epidemiologist and was an assistant professor at the time of the study. She has long-standing experience in nursing, qualitative research and evidence-based quality improvement. NG was an MSc candidate in the health and life sciences at the time of the study; qualitative research was part of the curriculum. No formal or hierarchical relationship with the participants, which might have inhibited open discussion, existed. A registered nurse with a postacademic degree and experience in qualitative research $(\mathrm{CO})$ was supportive for the data analysis.

\section{8 | Data analysis}

From May 2015 to August 2016, the interviews and focus groups were conducted, transcribed verbatim, analysed and coded, and clustered into categories and themes in Dutch. We used MAXQDA version 12 for this purpose. Two researchers (NG and $\mathrm{CO}$ ) independently analysed each transcript to establish trustworthiness and credibility.

Consensus about the codes, categories, themes and their meanings was reached during joint meetings. The researchers solved discrepancies by discussion. During the data analysis, it appeared that data saturation had not been reached for the combined "education - clinical practice" role. Therefore, an extra interview was conducted in December 2016 to reach data saturation.

So that we could include positive cases and check the identified themes, two nurse academics from the United Kingdom, who had experience with clinical academic career pathways, were interviewed and their input was added to the sample (Table 1). Additionally, three senior researchers from other Dutch universities were asked to reflect on the investigators' interpretation of the results. They agreed about the identified themes.

\section{9 $\mid$ Ethical considerations}

The local Institutional Review Board (Academic Medical Center, Amsterdam, the Netherlands) approved the study and concluded that further ethical approval of this study was not required under Dutch legislation (see www.ccmo.nl/en/). Permission for this study was obtained from the nursing directors.

The participants received a full explanation of the study prior to the focus groups and interviews, and they gave oral informed consent and permission for audio-recording. All data were to remain confidential, and the anonymity of the participants was guaranteed by dissociation of names. Data were saved under identification numbers, which were allocated at random and preserved by one of the researchers (NG).

\section{3 | RESULTS}

\section{1 | Perceived importance of combining clinical and academic work}

The analysis showed that most participants were convinced of the positive contribution of clinical nurse academics to excellent patient care due to the mutual benefits created by the combination of clinical and academic work. For example, clinical nurse academics could deliver more clinically relevant education, establish more clinically relevant research questions and might implement research results more successfully. Nonetheless, a staff advisor stated that a good researcher or 
Oostveen, C.J. van, Goedhart, N.S., Francke, A.L., Vermeulen, H. Combining clinical practice and academic work in nursing: a qualitative study about perceived importance, facilitators and barriers regarding clinical academic careers for nurses in university hospitals. Journal of Clinical Nursing: 2017, 26(23-24), 4973-4984

teacher does not need to combine educational work or research with clinical practice: It is not necessary for a nurse scientist to work in clinical practice as well.. . . I do not think it is necessary for any type of research. Staff advisor (4) Most participants were also convinced of the positive effects of implementing clinical academic career pathways for nurses in hospitals to promote clinical academic careers. They believed that the implementation would positively affect the personnel outcomes because the pathway provides nurses with a chance of obtaining a more challenging and enjoyable job. Furthermore, several participants said that the implementation also positively affected the hospitals' image as an attractive employer for highly motivated and talented nurses: Of course it will improve your image as an interesting employer for nurses. That part of a hospital's image is very interesting because we prefer to attract talented and more highly educated nurses. Medical director (21) The academic nurses who participated in this study represented all possible combined roles, for example, research-education, research-practice and practice-education. One participant combined all three roles.

When we focused on combining clinical and academic work, three main themes emerged from the data analysis: culture, leadership and infrastructure. These themes are closely related to each other and have a major impact on the opportunities for nurses to combine clinical and academic work in hospitals.

\section{2 | Culture: facilitators and barriers}

\subsubsection{Academic culture}

Most participants said that the increased organisational attention regarding the trias academica (patient care, research and education) in the medical era is a facilitator for combining clinical and academic work. They argued that physicians already combine clinical and academic work, in contrast to nurses. Therefore, the current knowledge of human resource policy, remuneration structure, supportive infrastructure and funding should be used to develop and implement clinical academic career pathways for nurses.

Nurse academics stated that the combination research-practice and researcheducation are more valued in the academic culture than the practice-education combination, as publishing is paramount in academia - as we know all too well, "publish or perish". Furthermore, the salaries in the universities of applied sciences are more attractive to nurse academics if they combine research and education: So, if you are appointed to a university of applied sciences, the trend will then very quickly become "let's do research". Management discourages combining all three aspects of the trias academica. Apart from organizational difficulties, one of the nursing directors once said to me, 'You are a serious threat to patient safety if you work in patient care for only 1 day a week.' Nurse academic (24)

\subsubsection{Nursing as an academic misfit}

The participants stated that, while the academic culture smiles on the combination of clinical and academic work for physicians, other cultural issues hamper such a combination for nurses. For instance, direct patient care is the first priority for nurses and nurse managers, which implies that research and education are not: Nurses sitting behind a desk the entire day will be appreciated differently than nurses standing beside a bed uselessly chatting with the patient because then someone takes care of a patient. Nurses appreciate 
Oostveen, C.J. van, Goedhart, N.S., Francke, A.L., Vermeulen, H. Combining clinical practice and academic work in nursing: a qualitative study about perceived importance, facilitators and barriers regarding clinical academic careers for nurses in university hospitals. Journal of Clinical Nursing: 2017, 26(23-24), 4973-4984

research less because, in their opinion, it has no direct impact on an individual nivel patient. Nurse academic (3) The participants asserted that the under-appreciation of academic tasks in nursing teams has a major impact on nurses who combine clinical practice with research or education. For example, nurses working in a team that focuses mainly on direct patient care may get negative reactions from their colleagues when they are working on academic tasks. Some participants reported a high level of peer pressure in nursing teams, which is viewed as a causal factor for the limited number of talented nurses who start a clinical academic career: In our profession, there is high peer pressure in teams.

It's a typical Dutch thing: 'Don't stand out in a crowd, just do what everybody else does'. Which is killing. There are many talented nurses with ambition who don't dare stand out in a crowd. Nursing director (9) Furthermore, the participants were concerned that recently graduated nurses would lose the preacademic skills that they developed during their education as soon as they started working in a team that focused solely on direct patient care: As soon as you let them go, nothing more happens. They do not take the initiative in practice because they focus so primarily on their team and their patients. And then they unlearn their abstract thinking skills. Nurse academic (1) The strong focus on direct patient care also influences the physician- nurse relationship because of the rigid hierarchy still present in hospitals, which places physicians in charge and in leading positions with budgets. Nurses still do not succeed in claiming their own domain and positions: We, as nurses, always have the feeling that we are subordinate to physicians. This is not supporting at all. Nurse academic (6) The participants declared that when nurses see themselves as subordinates, it influences the combination of clinical and academic work negatively because it limits them in their autonomy and authority in direct patient care, as well as in their academic work.

To encourage combining clinical practice and academic work, a nurse-physician relationship of equality is needed. Several participants, including medical directors and academically trained physicians, said that such a relationship can be established by working in interprofessional teams, participating in interprofessional training and speaking the same scientific language. Moreover, strong track records in nursing research will receive respect from physicians. Physicians would be happy to collaborate with such nurses: "Of course you have to have a strong track record to join on a grant. That's the way it is. You just have to have a good track record and match the theme." Academic physician (19) However, some participants felt that some physicians or institutions did not see any point in nurses combining clinical and academic work. One of the nurse academics pointed out that the public image of nursing as a practical job is the main cause for under-appreciation of nursing research by others: There are still physicians who say, 'Nurses have to wash people's behinds'. Nurse academic (20) Unfamiliarity also has an impact on the appreciation with nursing research. Nurse academics reported that physicians are sometimes surprised that nurses can obtain a $\mathrm{PhD}$ : I am a post-doctoral nurse, and recently a physician asked me, "Why did you do a PhD? Isn't that absolutely useless for nurses?" Yes, that really leaves me dumbfounded.

Nurse academic (1) Others stated that an occupation such as "clinical academic" is clearly understood by physicians, which is favourable for the implementation of this role for nurses. 
Oostveen, C.J. van, Goedhart, N.S., Francke, A.L., Vermeulen, H. Combining clinical practice and academic work in nursing: a qualitative study about perceived importance, facilitators and barriers regarding clinical academic careers for nurses in university hospitals. Journal of Clinical Nursing: 2017, 26(23-24), 4973-4984

\section{3 | Leadership: facilitators and barriers}

\subsubsection{Nonfacilitating organisational leadership}

Although there are internal documents that underline the necessity of academic work for nursing, several participants pointed out that a clear mission and clear vision, which highlight the importance of nurses excelling in the trias academica, currently do not exist. Some participants recognised this as the lack of commitment of leaders at the strategic level: If they do not want this (academic careers for nurses - red.) we should stop the discussion about it. It is like a carrot on a stick. A bottom-up approach is not enough! Academic nurse (24) Most participants said that nursing directors can and should help nurses combine clinical and academic work. The nurse academics from the United Kingdom specifically highlighted the need of champions in line management for creating clinical academic job opportunities: They should propagate it; they should shout out loud about the importance of nursing research and education.

They are the advertisers of the nursing culture in a hospital.

Clinical educator (15)

However, current nursing directors would focus too much on the primary processes instead of on vision, mission and strategic goals or strategies to achieve these goals: Managers focus on financials and direct patient care, while they see research as a hobby. Nursing director (9) All the nursing directors agreed about this. They said they have a positive attitude towards the combination of clinical and academic work for nurses. However, the main reason the focus is not more on academic work is their personal inadequate academic knowledge and competencies for integrating clinical and academic work.

\subsection{2 | Role models' credibility}

All the participants were able to identify good examples of nurse academics. They pointed out that current nurse academics obtain tangible results, such as published scientific articles and grants. However, they believed nurse academics needed to be more visible in the hospital: "Make yourself visible; tell everyone what your value for direct patient care and for the nursing profession is. ...You need to get or create a podium." Nursing director (5) The participants named two causes for the invisibility of the nurse academics. First, nursing directors do not yet facilitate a platform for nurse academics. Second, the nurse academics should be heard, but it seems that they do not have the leadership competencies to make themselves visible: What is important is that managers and boards of directors should more often give these people a platform. So that one becomes aware of the importance and impact of nursing research. That it becomes clearer. Then people would be excited. Nurse manager (10) Make yourself visible. We have role models in research, but they are not visible enough. Nurse manager (5) And the nurse specialists themselves ... some are interested in doing research, but they do not make their voices heard. They still have not explained to those in other disciplines why nursing research is an important part of their job. Nurse academic (2) Nurse academics experience difficulties in connecting with the frontline nurses because they no longer do clinical work. While the nurse academics said they would love to combine clinical and academic work, directors and managers believed that academically trained nurses tend to focus solely 
Oostveen, C.J. van, Goedhart, N.S., Francke, A.L., Vermeulen, H. Combining clinical practice and academic work in nursing: a qualitative study about perceived importance, facilitators and barriers regarding clinical academic careers for nurses in university hospitals. Journal of Clinical Nursing: 2017, 26(23-24), 4973-4984

on their academic work: To me, it seems nurses have a goal not to wear their uniforms, and with that they subvert the whole system.

If I ask, 'Why don't you want to work 1 day in direct care?', they look at me as if I had said something very dirty. Medical director (21) Good examples of nurse academics are needed to change the attitudes towards nurses combining clinical and academic work, or at least doing academic work. These nurses are trusted by their frontline colleagues and their research results will have more impact on patient care: Trust and authority influence the implementation of the research results. Researchers with direct hands-on experience will get more respect and nurses will trust them more easily. Human resources manager (13)

\section{4 | Infrastructure: facilitators and barriers}

\subsubsection{Limited career ladder}

The limited career opportunities for nurses with a master's or $\mathrm{PhD}$ degree in hospitals were considered the main reason why nurses do not combine clinical and academic work. Moreover, academic qualifications are not required for any nursing role except advanced nurse practitioners: Post-doctoral students will lose their jobs or get jobs as lecturers. No other options are left. Nurse academic (12) All the participants said that a shift in the employment structure is needed to improve the retention of nurse academics in hospitals.

Formal clinical academic positions need to be created to ensure that nurses will be able to do clinical work as well as academic work: Do you really want this ... work an evening shift and start your research day at 8 am the next morning. Combining practice and education is even harder because those rostering schemes are very static. Nurse academic (24) Formal positions also facilitate a suitable remuneration structure.

The nurse academics pointed out that, at that moment, working in hospitals was not that attractive because they earned less than policy advisors or lecturers at the university of applied sciences, for instance. Furthermore, combining research (or education) and practice implied a flexible salary: If you start or continue working in direct patient care after you get your $\mathrm{PhD}$, your salary will drop.

Academic nurse (3)

Most participants recognised the need of finances to promote and facilitate clinical academic careers by implementing clinical academic career pathways for nurses. However, finances are difficult because hospitals are constantly dealing with reimbursement issues: In times of shortage, implementation is difficult, but in financially good times it will be easier to invest in such trajectories . . Currently, we live in a difficult time, but this will end someday. Academic physician (19)

\subsection{2 | Collaboration for success}

All the participants agreed that good funding infrastructure was indispensable. However, because there is no tradition of applying for funding, nurse academics experience difficulties in writing grant proposals.

Therefore, they emphatically recommended creating an integrated research infrastructure in which nurses can use the knowledge, resources and networks of physicians and other academics to increase their funding skills and successes. This was also recognised as a facilitating factor in the academic culture: Well, I think there's a very strong medical infrastructure with a lot of know-how. It would be 
Oostveen, C.J. van, Goedhart, N.S., Francke, A.L., Vermeulen, H. Combining clinical practice and academic work in nursing: a qualitative study about perceived importance, facilitators and barriers regarding clinical academic careers for nurses in university hospitals. Journal of Clinical Nursing: 2017, 26(23-24), 4973-4984

stupid to build your own nursing silo. So take advantage of all the know-how that is already in place. Nursing director (11) Some participants went even further on the subject of interprofessional collaboration: they argued for nursing research comparable to medical research lines so that it would be successful: You shouldn't see nursing research as separate from medical research. There is a practical reason. Nurses do not have many chances to apply for grants independently, and it makes no sense to do research that is not aligned with the organizational medical priorities. That would be hopeless. Nursing director (9)

\section{4 |DISCUSSION}

Perceptions of nurses combining clinical and academic work comprise three critical components for successful development of research capacity and capability: culture, leadership and infrastructure (Segrott et al., 2006; Weir \& Ozga, 2011). These components, or themes, highlight the deficiencies in the facilitation of clinical academic careers for nurses. The themes also reveal rich information about the barriers and facilitators that arise in implementing a clinical academic career pathway. Nevertheless, the participants in our study were generally positive about the mutual benefit of combining clinical and academic work for patients and themselves, and they emphasised the need of clinical academic posts for nurses.

\section{1 | Culture}

According to our participants, current nursing culture hampers nurses in combining clinical and academic work. In general, nursing teams focus on direct patient care and under-appreciate academic tasks such as research and education. Moreover, the nurses themselves seem to hinder colleagues who are developing academic competencies. These findings are in line with the findings in studies by the UKCRC (2007, p 17) and van Oostveen et al. (2015, p1307) who describe the nursing culture as "anti-academic" and "basic-functional". Nurses are satisfied with results that are directly visible and usable in practice, not with long-term research projects (Roxburgh, 2006). Therefore, the fact that physicians and others do not identify nursing with academic work seems to be a selffulfilling prophecy. The physicians confirmed this when they said they would be happy to collaborate with nurses who have strong academic track records. However, the definition of "strong" may be unclear because the physicians and managers did not seem to be convinced of the legitimacy and uniqueness of nursing research. This can be interpreted as "medical dominance" regarding what is necessary for highquality patient care and what constitutes an academic career. In general, nurses regard the clinical career as the most important one (Loke, Laurenson, \& Lee, 2014; Roxburgh, 2006). This can partly be traced back to the preprofessional history of nursing (Gonz_alez \& Mdel, 2011), but it is also comprehensible because most nurses in the Netherlands are trained at the vocational level, in which nursing research is not a part of the curriculum. In addition, the professional nursing register in the Netherlands does not differentiate between bachelor and vocational nursing training, which leads to one generalist job profile in clinical practice and the equalisation of the two training levels. Hence, developing a clinical research environment that provides opportunities for nurses to pursue research careers and strong academic track records can be a real challenge. Latter et al. (2009) describe the lack of strong track records as a threat to the implementation of clinical academic career pathways for nurses due to the fact that publishing is paramount in the academic world. Nurses should, therefore, be 
Oostveen, C.J. van, Goedhart, N.S., Francke, A.L., Vermeulen, H. Combining clinical practice and academic work in nursing: a qualitative study about perceived importance, facilitators and barriers regarding clinical academic careers for nurses in university hospitals. Journal of Clinical Nursing: 2017, 26(23-24), 4973-4984

given clear roles and positions within the hospital organisation, and they should have protected time to do academic work (Kim, 2009).

Positioning nurse academics in clinical practice has already been proven to promote knowledge transfer and the use of evidence in nursing practice; this eventually leads to greater cost-effectiveness in nursing care (Staffileno et al., 2013). Mainstreaming clinical academic careers could be a powerful lever for increasing research and educational activities in hospitals, as well as for delivering safe and high-quality care to patients.

\section{2 | Leadership}

Leadership is essential to the success of developing clinical academic careers for nurses (Weir \& Ozga, 2010). Apparently, our respondents are not given the leadership or perseverance authority to facilitate, motivate and organise the development of clinical academic careers.

This leadership seems to be absent at every level in the hospital organisation. There is no clear vision regarding the added value to patient care and career opportunities for nurses at the strategic level; no manager at the tactical level feels responsible for it. At the primary level, nurses are under serious peer pressure to stay at the bedside. In this study, managers criticised nurse academics for their invisibility in practice. Is it fair to blame our nurse academics for the absence of managerial support, good role models, mentors and research teams? Mentoring and role modelling by more experienced nurse academics help to develop academic skills and a stable academic identity (Logan et al., 2016; Robichaud-Ekstrand, 2016).

Furthermore, collaboration with peers helps new nurse academics gain confidence (Hemmings \& Kay, 2010). The identity transition from practitioner to nurse academic has been estimated to take 3 years (Murray, Stanley, \& Wright, 2014), but it may take even longer without a formal nursing research team.

To help nurse academics become leaders in clinical research, it is necessary to select and retain nurse academics with excellent qualifications (Girot (Rosser), 2011; Robichaud-Ekstrand, 2016).

Once established, these nurse academics will provide an environment in which students and nurses can be captivated and encouraged to develop academic careers themselves. Such an environment is much needed: in 2015, only seven of 2,727 fulltime professors had a nursing chair in the Netherlands (VSNU 2015). This illustrates how much still has to be done before we have created a critical mass for the nursing profession. Policy development at the governmental level to address these issues is necessary, in addition to the local initiatives. Such policies could influence initiatives to promote nursing research and develop clinical academic careers for nurses. For instance, in the UK, the government and the National Health Service boards formed task forces and wrote reports to increase the uptake of the evidence base in nursing for high-quality patient care and laid the foundation for clinical academic careers (UK Clinical Research Collaboration (UKCRC), 2007; Weir \& Ozga, 2010; Weir \& Ozga, 2011). Such initiatives create a sense of urgency for organisations and healthcare managers. These groups may not realise that clinical academic careers for nurses are pivotal for the evidence base in nursing and knowledge transfer to clinical practice. To learn more, we also turned to Australia, the USA and Canada, where different models for clinical academic posts or joint roles have been developed and implemented to bridge the gap between academia and nursing practice. The successes of these initiatives should be interpreted in the 
Oostveen, C.J. van, Goedhart, N.S., Francke, A.L., Vermeulen, H. Combining clinical practice and academic work in nursing: a qualitative study about perceived importance, facilitators and barriers regarding clinical academic careers for nurses in university hospitals. Journal of Clinical Nursing: 2017, 26(23-24), 4973-4984

context of the development of nursing research in these countries, the healthcare systems and the differences in the status of nursing (Weir \& Ozga, 2010). Nevertheless, we note that all the initiatives allocated resources to establish infrastructure, and these resources are crucial to the success of clinical academic posts and therefore careers for nurses (Kim, 2009). Furthermore, support at the strategic and tactical levels is indispensible in facilitating these nurse academics. Clearly defined roles, remuneration structures, robust partnerships between the hospital on the one hand and the medical university and university of applied sciences on the other hand, and a dedicated clinical chair are crucial for powerful positioning and successful implementation of a clinical academic career pathway (Latter et al., 2009; Logan et al., 2016). Therefore, managers should realise that they have a key role in furthering clinical academic careers for nurses. To overcome the managerial knowledge deficiencies and the priority issues addressed by the participants, it is necessary to involve managers in the research and improve the influence of nurse academics at the strategic and tactical levels, for example, by adjusting job requirements for nursing managers according to the medical model or by appointing a Chief Nursing Officer who promotes the interests of nurse academics (Weir \& Ozga, 2010).

\section{3 $\mid$ Infrastructure}

Nurse academics noted the absence of suitable job opportunities such as doctoral scholarships and postdoctoral research fellowships for nurses. This is a reflection of the current level of the research culture in nursing. Without a fostering research culture, almost half the nurses who have PhDs stop doing research (Al-Nawafleh, Zeilani, \& Evans, 2013). This implies a significant leakage of academic knowledge and skills that are needed to provide high-quality patient care, and this waste of talent is costly (Buchan, 1999; O’Brien-Pallas, Murphy, Shamian, Li, \& Hayes, 2010). For mainstream clinical academic careers for nurses, it is important to implement "embedded pathways based on consolidated funding and increased numbers of substantive posts" (Latter et al., 2009; p 141). The nurse academics in this study experienced the absence of suitable funding infrastructures as a major barrier to combining clinical and academic work. Unlike physicians, nurses in the Netherlands have no history of integrated contracts which allows them to combine clinical practice and academic work. Therefore, an infrastructure for combining clinical and academic work needs to be developed in collaboration with human resource officers, that is, in relation to job descriptions, employment contracts, salary scales and secondary benefits (Latter et al., 2009).

Without such an infrastructure, the largest portion of the money for conducting doctoral or postdoctoral nursing research should come from grants. However, not many nurse academics apply for grants, which implies that the network is vulnerable and there is a need for better skills to apply for grants. Nurse academics should collaborate with other, already established, research groups to obtain opportunities for mentoring and developing skills that are valued by grand awarding bodies and university promotion panels, for example. Collaboration also generates focus when medical and nursing research lines and education are being integrated.

Such a shared vision could be a powerful tool for obtaining resources and infrastructure for conducting research and delivering high-quality patient care (Macleod Clark, 2014). It also may lead to a better understanding of the unique 
Oostveen, C.J. van, Goedhart, N.S., Francke, A.L., Vermeulen, H. Combining clinical practice and academic work in nursing: a qualitative study about perceived importance, facilitators and barriers regarding clinical academic careers for nurses in university hospitals. Journal of Clinical Nursing: 2017, 26(23-24), 4973-4984

contribution of nursing research, for example, holistic perspectives or improvement of patient-relevant outcomes that are sensitive to nursing. Such matters are crucial to the evidence base in health care and to high-quality patient care.

\section{4 | Limitations}

Some limitations in this study warrant consideration. First, our study took place in only two of the eight Dutch university hospitals (including the medical faculties and affiliated universities of applied sciences). Although the results have been shared with four nurse academics working in other university hospitals in the Netherlands who agreed on the identified themes, evaluation resonance and the practical suitability of the results are matters for the readers to judge. Second, researchers leaving academia to go to institutions other than the affiliated universities of applied sciences were not captured, which could have caused bias.

\section{5 | CONCLUSION}

Our study participants placed much value on clinical academic careers, but current nursing culture, perceptions of the added value of nursing research, and the lack of leadership for nurse academics and the lack of infrastructure hinder the development and implementation of these roles. To overcome these barriers, we must emphasise the importance of clinical academic careers for nurses because of the contributions they generate for the nursing evidence base and the use of research findings in clinical practice.

\section{6 | RELEVANCE TO CLINICAL PRACTICE}

Improving the research culture in nursing would lead to the development and implementation of clinical academic career pathways. This would also suit the current aspirations of the health service in the Netherlands, who want to anchor the difference between vocational and bachelor-trained nurses in the Dutch national nursing register. In addition, a new bachelor nursing curriculum including emphasis on developing leadership, research and analytic skills has been developed to prepare nurses for the current and upcoming challenges in healthcare (Lambregts \& Grotendorst, 2012; Terpstra et al., 2015). These developments represent an acknowledgement of the need for knowledge generation and implementation of a forward-facing discipline.

\section{ACKNOWLEDGEMENTS}

We thank the many interviewees for their willingness to share their experiences about nurses combining clinical and academic work in this study. We are also grateful to the senior researchers from other Dutch universities for their reflections on our interpretation of the results.

\section{CONFLICT OF INTEREST}

The authors declare that they have no competing interests.

\section{DISCLOSURE}

The authors have confirmed that all authors meet the ICMJE criteria for authorship credit (www.icmje.org/ethical_1author.html), as follows: (1) substantial contributions to conception and design, acquisition of data, or analysis and interpretation of data; (2) drafting the article or revising it critically for important 
Oostveen, C.J. van, Goedhart, N.S., Francke, A.L., Vermeulen, H. Combining clinical practice and academic work in nursing: a qualitative study about perceived importance, facilitators and barriers regarding clinical academic careers for nurses in university hospitals. Journal of Clinical Nursing: 2017, 26(23-24), 4973-4984

intellectual content; and (3) final approval of the version to be published ORCID Catharina J. van Oostveen http://orcid.org/0000-0002-3483-2206

\section{REFERENCES}

Aiken, L., Cimiotti, J., Sloane, D., Smith, H., Flynn, L., \& Neff, D. (2011).

The effects of nurse staffing and nurse education on patient deaths in hospitals with different nurse work environments. Medical Care, 49, 1047-1053.

Al-Nawafleh, A., Zeilani, R., \& Evans, C. (2013). After the doctorate: A qualitative study investigating nursing research career development in Jordan. Nursing \& Health Sciences, $15,423-429$.

AUKUH Clinical Academic Careers Group for Nursing and Midwifery (2013). The nurse and midwife research clinical academic: Development, progress and challenges. London: The Association of UK University Hospitals.

Buchan, J. (1999). Evaluating the benefits of a clinical ladder for nursing staff: An international review. International Journal of Nursing Studies, 36, 137-144.

Coombs, M., Latter, S., \& Richardson, A. (2012). Developing a clinical academic career pathway for nursing. British Journal of Nursing, 21, 1084-1086-1090.

De Jonge, J. (2016). Practice-based research at research groups of universities of applied sciences [Praktijkgericht onderzoek bij lectoraten van Hogescholen]. Facts and numbers 19[Feiten \& Cijfers 19]. The Hague: Rathenau Instituut. Retrieved from https://www.rathenau.nl/nl/publi catie/praktijkgericht-onderzoek-bij-lectoraten-vanhogescholen

Erlandson, D., Harris, E., Skipper, B., \& Allen, S. (1993). Doing naturalistic inquiry: A guide to methods. Newbury Park, CA: Sage Publications Inc.

Eskes, A., Storm-Versloot, M., Vermeulen, H., \& Ubbink, D. (2012). Do stakeholders in wound care prefer evidence-based wound care products? A survey in the Netherlands. International Wound Journal, 9, 624-632.

European Union (EU) (2014). Regulation (EU) No 282/2014 of the European Parliament and of the Council of 11 March 2014 on the establishment of a third Programme for the Union's action in the field of health (2014-2020) and repealing Decision No 1350/2007/EC Text with EEA relevance. Retrieved from http://eur-lex.europa.eu/legal-content/EN/ TXT/?uri=CELEX:32014R0282

Girot (Rosser), E. (2011). Shaping clinical academic careers for nurses and allied health professionals: The role of the educator. Journal of Research in Nursing, 18, 51-64.

Gonz_alez, S. J., \& Mdel, R. C. (2011). Cultural history and aesthetics of nursing care. Revista latino-americana de enfermagem, 19, 1096-1105.

Helfrich, C., Weiner, B., Mckinney, M., \& Minasian, L. (2007). Determinants of implementation effectiveness adapting a framework for complex innovations. Medical Care Research and Review, 64, 279-303.

Hemmings, B., \& Kay, R. (2010). Research self-efficacy, publication output, and early career development. International Journal of Educational Management, 24, 562-574.

Kim, M. (2009). Clinical academic research careers in nursing: Towards global nursing. Journal of Research in Nursing, 2, 125-132.

Lambregts, J., \& Grotendorst, A. (2012). Leren van de toekomst. Houten: Bohn en Stafleu van Lochum. Retrieved from http://www.venvn.nl/ LinkClick. aspx?fileticket=fO31 mxBkHV0=\&tabid $=5145 \% 5$ Cnwww.bsl.

nl Latter, S., Clark, J., Geddes, C., \& Kitsell, F. (2009). Implementing a clinical academic career pathway in nursing; criteria for success and challenges ahead. Journal of Research in Nursing, 14, 137-148.

Latter, S., Richardson, A., \& Fader, M. (2010). Clinical academic role descriptors: research. Southampton. Retrieved from http://eprints.so ton.ac.uk/166853/1/CA_research_role_descriptors.pdf Logan, P., Gallimore, D., \& Jordan, S. (2016). Transition from clinician to academic: An interview study of the experiences of UK and Australian Registered Nurses. Journal of Advanced Nursing, 72, 593-604.

Loke, J., Laurenson, M., \& Lee, K. (2014). Embracing a culture in conducting research requires more than nurses' enthusiasm. Nurse Education Today, 34, 132-137. 
Oostveen, C.J. van, Goedhart, N.S., Francke, A.L., Vermeulen, H. Combining clinical practice and academic work in nursing: a qualitative study about perceived importance, facilitators and barriers regarding clinical academic careers for nurses in university hospitals. Journal of Clinical Nursing: 2017, 26(23-24), 4973-4984

Macleod Clark, J. (2014). Clinical academic leadership - Moving the profession forward Journal of Research in Nursing, 19, 98-101.

Murray, C., Stanley, M., \& Wright, S. (2014). The transition from clinician to academic in nursing and allied health: A qualitative meta-synthesis.

Nurse Education Today, 34, 389-395.

O'Brien-Pallas, L., Murphy, G. T., Shamian, J., Li, X., \& Hayes, L. J. (2010).

Impact and determinants of nurse turnover: A pan-Canadian study.

Journal of Nursing Management, 18, 1073-1086.

Oude Rengerink, K., Zwolsman, S. E., Ubbink, D. T., Mol, B. W. J., van Dijk, N., \& Vermeulen, H. (2013). Tools to assess evidence-based practice behaviour among healthcare professionals. Evidence-Based Medicine, 18, 129-138.

Ozsoy, S., \& Ardahan, M. (2008). Research on knowledge sources used in nursing practices. Nurse Education Today, 28, 602-609.

Polit, D., \& Beck, C. (2012). Nursing research: Generating and assessing evidence for nursing practice (9th ed.). Philadelphia, PA: Wolters Kluwer Health/Lippincott Williams \& Wilkins.

Robichaud-Ekstrand, S. (2016). New Brunswick nurses' views on nursing research, and factors influencing their research activities in clinical practice. Nursing \& Health Sciences, 18, 246-255.

Roxburgh, M. (2006). An exploration of factors which constrain nurses from research participation. Journal of Clinical Nursing, 15, 535-545.

Segrott, J., Mclvor, M., \& Green, B. (2006). Challenges and strategies in developing nursing research capacity: A review of the literature. International Journal of Nursing Studies, 43, 637-651.

Staffileno, B., Wideman, M., \& Carlson, E. (2013). The financial and clinical benefits of a hospital-based PhD nurse researcher. Nursing Economic\$, 31, 194-197.

Tassoul, M., \& Buijs, J. (2007). Clustering: An essential step from diverging to converging. Creativity and Innovation Management, 1, 16-26.

Terpstra, D., van den Berg, A., van Mierlo, C., Zijlstra, H., Landman, J., Schuurmans, M., \& Kempff, M. (2015). Future-proof occupations in the nursing [Toekomstbestendige beroepen in de verpleging en verzorging: Rapport stuurgroep over de beroepsprofielen en de overgangsregeling].

Retrieved from http://www.venvn.nl/Portals/1/Nie uws/2016\%20Documenten/20160113\%20Rapport\%20Toekomstbest endige\%20beroepen.pdf Tong, A., Sainsbury, P., \& Craig, J. (2007). Consolidated criteria for reporting qualitative research (COREQ): A 32 -item checklist for interviews and focus groups. International Journal for Quality in Health Care, 19, 349-357.

Ubbink, D., Guyatt, G., \& Vermeulen, H. (2013). Framework of policy recommendations for implementation of evidence-based practice: A systematic scoping review. British Medical Journal Open, 3, e001881.

UK Clinical Research Collaboration (UKCRC) (2007). Developing the best research professionals. Report of the UKCRC Subcommittee for nurses in clinical research (workforce), [Finch Report] London: UKCRC.

Retrieved from http://www.ukcrc.org/wp-content/uploads/2014/07/ Nurses-report-August-07Web.pdf van Oostveen, C., Mathijssen, E., \& Vermeulen, H. (2015). Nurse staffing issues are just the tip of the iceberg: A qualitative study about nurses' perceptions of nurse staffing. International Journal of Nursing Studies, 52, 1300-1309.

VSNU Association of Dutch Universities [Vereniging Samenwerkende Nederlandse Universiteiten (VSNU)]. (2015). Science Education Personnel Information 2015 [Wetenschappelijk Onderwijs Personeels Informatie (WOPI) 2015]. Retrieved from http://www.vsnu.nl/nl_NL/f_c_person eel_downloads.html Wangensteen, S., Johansson, I., Bj€orkstr€om, M., \& Nordstr€om, G. (2011).

Research utilisation and critical thinking among newly graduated nurses: Predictors for research use. A quantitative cross-sectional study. Journal of Clinical Nursing, 20, 24362447.

Weir, A., \& Ozga, J. (2010). Clinical academic posts for nursing: A literature review. University of Edinburgh. Retrieved from http://www.ce s.ed.ac.uk/PDF\%20Files/CNO_LR.pdf Weir, A., \& Ozga, J. (2011). Clinical academic posts 
Oostveen, C.J. van, Goedhart, N.S., Francke, A.L., Vermeulen, H. Combining clinical practice and academic work in nursing: a qualitative study about perceived importance, facilitators and barriers regarding clinical academic careers for nurses in university hospitals. Journal of Clinical Nursing: 2017, 26(23-24), 4973-4984

for nursing: NHS Lothian case study. University of Edinburgh. Retrieved from http:// www.ces.ed.ac.uk/old site/PDF\%20Files/CNO CS01.pdf 
Oostveen, C.J. van, Goedhart, N.S., Francke, A.L., Vermeulen, H. Combining clinical practice and academic work in nursing: a qualitative study about perceived importance, facilitators and barriers regarding clinical academic careers for nurses in university hospitals. Journal of Clinical Nursing: 2017, 26(23-24), 4973-4984

\section{TABLES FIGURE, BOX}

TABLE 1 Interviewee characteristics

\begin{tabular}{|c|c|c|c|c|c|c|}
\hline & $\begin{array}{l}n \\
\text { Hosp } \\
1\end{array}$ & $\begin{array}{l}n \\
\text { Hosp } \\
2\end{array}$ & $\begin{array}{l}n \\
\text { UAS } \\
1\end{array}$ & $\begin{array}{l}n \\
\text { UAS } \\
2\end{array}$ & $\begin{array}{l}n \\
\text { UK }\end{array}$ & Total \\
\hline \multicolumn{7}{|l|}{ Gender } \\
\hline Male & 6 & 3 & & 1 & & 10 \\
\hline Female & 5 & 6 & 3 & & 2 & 16 \\
\hline \multicolumn{7}{|l|}{ Age (years) } \\
\hline $20-30$ & 2 & & 1 & & & 3 \\
\hline $31-40$ & 1 & 2 & & & & 3 \\
\hline $41-50$ & 3 & 1 & & & 2 & 6 \\
\hline$>50$ & 5 & 6 & 2 & 1 & & 14 \\
\hline \multicolumn{7}{|l|}{ Educational level } \\
\hline $\mathrm{BSC}$ & & 1 & & & & 1 \\
\hline MANP & & 2 & & & & 2 \\
\hline Master & 4 & 2 & 1 & & & 7 \\
\hline $\mathrm{PhD}$ & 7 & 4 & 2 & 1 & 2 & 16 \\
\hline \multicolumn{7}{|l|}{ Occupation } \\
\hline Nurse academic & 3 & 2 & 3 & 1 & 2 & 11 \\
\hline $\begin{array}{l}\text { Clinical } \\
\text { educator }\end{array}$ & 2 & 1 & & & & 3 \\
\hline Nursing director & 2 & 2 & & & & 4 \\
\hline HRM & 2 & 2 & & & & 4 \\
\hline Physician & 1 & 2 & & & & 3 \\
\hline Medical director & 2 & & & & & 2 \\
\hline Total & 11 & 9 & 3 & 1 & $\mathrm{x}$ & 24 \\
\hline
\end{tabular}

Hosp, hospital; UAS, University of applied sciences; UK, United Kingdom; BSc, Bachelor of Science; MANP, Master of Advanced Nursing Practice; PhD, Doctor of Philosophy; HRM, human resourcemanager; $X$, positive cases. 
Oostveen, C.J. van, Goedhart, N.S., Francke, A.L., Vermeulen, H. Combining clinical practice and academic work in nursing: a qualitative study about perceived importance, facilitators and barriers regarding clinical academic careers for nurses in university hospitals. Journal of Clinical Nursing: 2017, 26(23-24), 4973-4984

TABLE 2 Characteristics of focus group participants

\begin{tabular}{|c|c|c|c|}
\hline & $\begin{array}{l}\text { N } \\
\text { Hosp } 1\end{array}$ & $\begin{array}{l}N \\
\text { Hosp } 2\end{array}$ & Total \\
\hline \multicolumn{4}{|l|}{ Gender } \\
\hline Male & 4 & 1 & 5 \\
\hline Female & 2 & 7 & 9 \\
\hline \multicolumn{4}{|l|}{ Age (in years) } \\
\hline $20-30$ & 1 & 2 & 3 \\
\hline $31-40$ & 1 & 3 & 4 \\
\hline $41-50$ & 2 & & 2 \\
\hline$>50$ & 2 & 3 & 5 \\
\hline \multicolumn{4}{|l|}{ Educational level } \\
\hline LVN & 2 & & 2 \\
\hline $\mathrm{BSC}$ & 2 & 2 & 4 \\
\hline MSc & 2 & 4 & 6 \\
\hline $\mathrm{MSc}$ & & 2 & 2 \\
\hline \multicolumn{4}{|l|}{$\mathrm{PhD}$} \\
\hline \multicolumn{4}{|l|}{ Occupation } \\
\hline Senior nurse & 3 & 1 & 4 \\
\hline Clinical nurse specialist & & 2 & 2 \\
\hline Nurse academic & 1 & 1 & 2 \\
\hline \multicolumn{4}{|l|}{ Nursing director } \\
\hline \multicolumn{4}{|l|}{ Associate Professor } \\
\hline Other & 2 & 4 & 6 \\
\hline Total & 6 & 8 & 14 \\
\hline
\end{tabular}

Hosp, hospital; UAS, University of applied sciences; LVN, Licensed vocational Nurses; BSc, Bachelor of science; MSc, Master of science; PhD, Doctor of Philosophy. 
Oostveen, C.J. van, Goedhart, N.S., Francke, A.L., Vermeulen, H. Combining clinical practice and academic work in nursing: a qualitative study about perceived importance, facilitators and barriers regarding clinical academic careers for nurses in university hospitals. Journal of Clinical Nursing: 2017, 26(23-24), 4973-4984

\section{BOX 1 Interview prompts}

What do you think is the added value of nurses who combine clinical and academic work?

Topics: research — dinical practice and educational workdinical practice, patient care, personnel, organization

How do you feel about the culture in the organization regarding clinical academic careers for nurses?

Topics: facilitators, barriers, academia, publishing, nursing work environment

What do you think is needed to facilitate clinical academic careers for nurses?

Topics: innovation fit and value, management support, financial resources availability, innovation champions, clinical academic career pathway

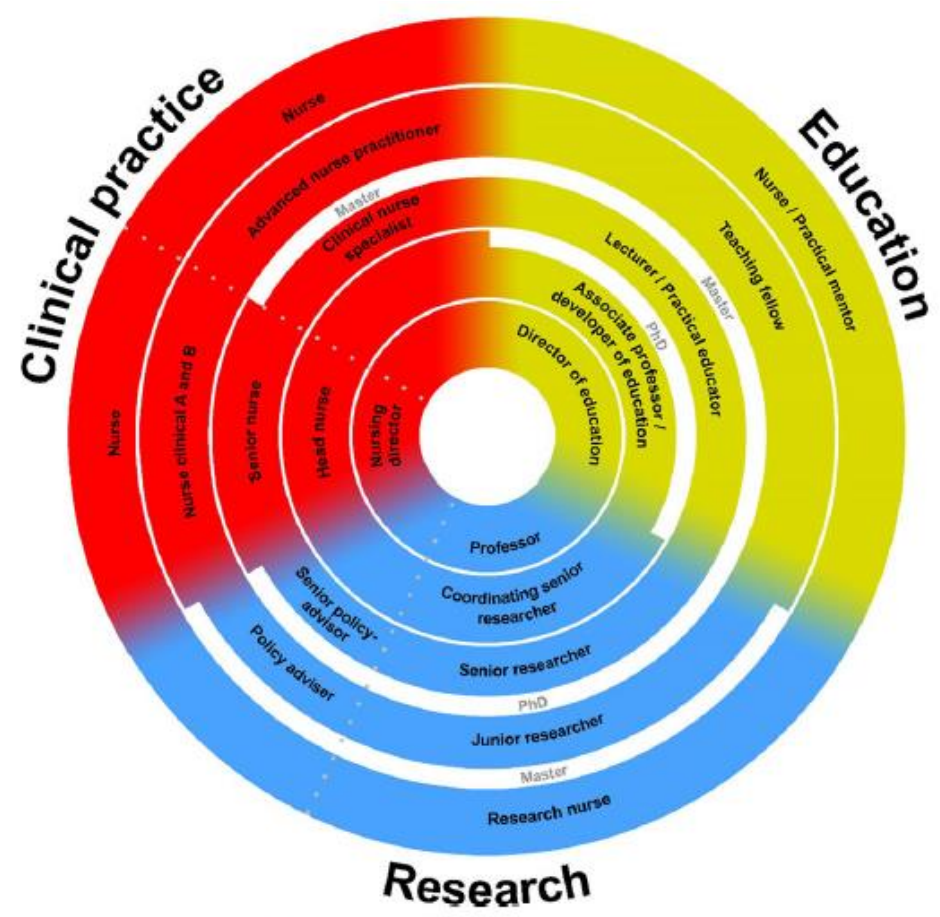

FIGURE 1 Dutch clinical academic career pathway. Underlying principles for the dinical academic career pathway for nurses. Clinical nurse academics:

- Pursue a single integrated job that includes at least one academic task in combination with dinical practice;

- Combine different layers of the circle, for instance, a nurse can have a job as junior researcher (layer three) in combination with a job as clinical nurse (layer one):

- Can move from one layer to the next if he or she has the right competencies. To start in the first layer, a clinical nurse academic must have at least a bachelor degree in nursing;

- Hold positions that are embedded in hospital 1 or 2 , in one of the affiliated universities of applied sciences or in a combination of the institutes [Colour figure can be viewed at wileyonlinelibrary.com] 